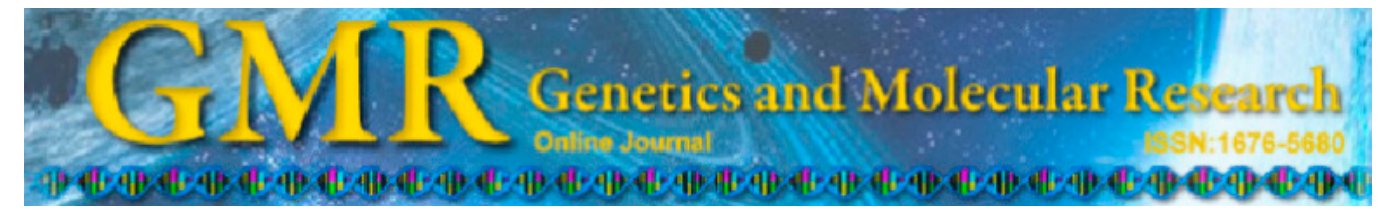

\title{
Efficient production of transgenic melon via Agrobacterium-mediated transformation
}

\author{
I. Bezirganoglu ${ }^{1,6}$, S.Y. Hwang ${ }^{2}$, J.F. Shaw ${ }^{3,4}$ and T.J. Fang ${ }^{1,5}$ \\ ${ }^{1}$ Department of Food Science and Biotechnology, \\ National Chung Hsing University, Taichung, Taiwan, China \\ ${ }^{2}$ Department of Entomology, National Chung Hsing University, \\ Taichung, Taiwan, China \\ ${ }^{3}$ Agricultural Biotechnology Research Center, Academia Sinica, Taipei, China \\ ${ }^{4}$ Department of Biological Science and Technology, I-Shou University, \\ Kaohsiung, Taiwan, China \\ ${ }^{5}$ Department of Nutrition, China Medical University, Taichung, Taiwan, China \\ ${ }^{6}$ Department of Molecular Biology and Genetics Erzurum Technical University, \\ Erzurum, Turkey \\ Corresponding author: T.J. Fang \\ E-mail: tjfang@nchu.edu.tw
}

Genet. Mol. Res. 13 (2): 3218-3227 (2014)

Received January 23, 2013

Accepted July 3, 2013

Published April 25, 2014

DOI http://dx.doi.org/10.4238/2014.April.25.7

ABSTRACT. Oriental melon (Cucumis melo L. var. makuwa) is an
important fruit for human consumption. However, this plant species
is one of the most recalcitrant to genetic transformation. The lack of
an efficient in vitro system limits the development of a reproducible
genetic transformation protocol for Oriental melon. In this study, an
efficient transgenic production method for Agrobacterium-mediated
transformation using cotyledon explants of Oriental melon was
developed. Cotyledon explants were pre-cultivated for two days in
the dark, and the optimal conditions for transformation of melon were
determined to be a bacteria concentration of OD ${ }_{600} 0.6$, inoculation for
30 min, and two days of co-cultivation. Transgenic melon plants were
produced from kanamycin-resistant shoots. A total of 11 independent
transgenic plants were regenerated with a transformation efficiency 
of $0.8 \%$ of the inoculated explants. The transgenic plants were phenotypically normal and fully fertile, which might be a consequence of the co-cultivation time.

Key words: Agrobacterium tumefaciens; nptII; Genetic transformation; Transgenic melon

\section{INTRODUCTION}

Genetic transformation complements traditional plant breeding in the development of transgenic plants. Economically important fruit crops will necessitate desirable agronomic traits to develop new cultivars, such as resistance to diseases and pests (Akasaka-Kennedy et al, 2004). In the last decade, genetic transformation methods have been developed for melon, watermelon, banana, and other plant species. Unfortunately, transformation is difficult in melon species due to the production of "escapes" and the selection of transgenic shoots because the cotyledon explants are inherently relatively resistant to kanamycin (Huang et al., 2011). Another major limitation in melon transformation is the poor formation of roots from transformed shoots due to vitrified shoots. In melon, as in many plant species, traditional breeding is the most common approach to develop new cultivars. However, the development of new cultivars by traditional breeding is restricted by intra- and inter-specific hybridization barriers, which inhibit the transfer of desirable agronomic characteristics into the genus. Moreover, the effectiveness of traditional breeding methods is deterred in melon due to the limited number of established cultivars, as well as inefficient selection and the time-consuming nature of the process. These factors have led to the development of novel strategies to obtain new cultivars, including molecular biology and genetic engineering (Bordas et al., 1997).

Transgenic technology has been successfully used to introduce and express various genes in many important plant species, including melon. There have been several studies on Agrobacterium-mediated transformation and plant regeneration in several melon species through cotyledon and leaf explants (Bordas et al., 1997; Galperin et al., 2003; Akasaka-Kennedy et al., 2004; Nuñez-Palenius et al., 2008; Chovelon et al., 2011; Ren et al., 2012). However, increased reproducibility and efficiency of stable transformation requires a combination of optimized factors, such as genotype, pre-cultivation time, inoculation time, co-cultivation period, concentration of selection agent, and culture medium composition. The transformation of melon was first achieved by Fang and Grumet (1990), who reported the first transgenic plants regenerated from cotyledon explants by Agrobacterium inoculation. Two important factors were used to manipulate the production of transgenic plants to obtain healthy shoots that were not vitrified with good rooting efficiency. The development of resistant varieties, such as the cucumber mosaic virus, watermelon mosaic virus, zucchini yellow mosaic virus (ZYMV) (Fuchs et al., 1998), and watermelon silver mottle virus (Huang et al., 2011), has been achieved in this crop through gene transfer technology. Other research groups have reported a genetic engineering approach to develop resistant melon plants through transformation with the ACC oxidase antisense gene (Nora et al., 2001; Nuñez-Palenius et al., 2008). However, there are few reports on the transformation system for Oriental melon (Cucumis melo L. var. makuwa 
cv. "Silver Light") (Choi et al., 2012; Wu et al., 2009). Therefore, this study developed such a transformation system by co-culturing cotyledon explants with the Agrobacterium strain LBA4404 containing the plasmid pBI121, which carries the AFP-CHI gene.

\section{MATERIAL AND METHODS}

\section{Plant material}

C. melo Silver Light seeds were obtained from Known-You Seed Co., Ltd. (Kaohsiung, Taiwan) and used as explants for melon transformation. The coats of the melon seeds were removed, and the surfaces of the seeds were sterilized with $1 \%$ sodium hypochlorite for $3 \mathrm{~min}$ and then washed three times with sterile distilled water. The sterile seeds were allowed to germinate on $1.5 \%$ water agar $\left(1.5 \mathrm{~g}\right.$ agar, $100 \mathrm{~mL}$ double-distilled $\left.\mathrm{H}_{2} \mathrm{O}\right)$ in the dark at room temperature for two days. Cotyledon explants were obtained from two day-old melon seedlings germinated in the dark. The surface-sterilized cotyledon explants from the seedlings were cut into eight segments and soaked in half MS liquid medium $\left(15 \mathrm{~mL} \mathrm{ddH_{2 }} \mathrm{O}, 15 \mathrm{~mL}\right.$ MS, pH 5.8) on a sterile Petri dish. Twenty seeds were placed into one Petri dish for bacterial inoculation. Approximately $30 \mathrm{~mL}$ medium was dispensed into disposable Petri dishes, after which $50 \mu \mathrm{L}$ overnight culture of Agrobacterium suspension $\left(\mathrm{OD}_{600}=0.6\right)$ was added; the components were then subjected to gentle, rotary shaking for $30 \mathrm{~min}$. All plant hormones and antibiotics used in this study were purchased from Sigma. The medium was adjusted to $\mathrm{pH}$ 5.7-5.8 with either $0.1 \mathrm{~N} \mathrm{KOH}$ or $0.1 \mathrm{~N} \mathrm{HCl}$, and $0.7 \%$ agar was added as a gelling agent. Then, the medium was autoclaved at $121^{\circ} \mathrm{C}$ for $20 \mathrm{~min}$. The cultures were kept under a $16 \mathrm{~h}$ photoperiod with a light intensity of $25-30 \mu \mathrm{E} \cdot \mathrm{m}^{2} \cdot \mathrm{s}$ provided by $40 \mathrm{~W}$ cool white fluorescent lamps. They were maintained at $28^{\circ} \mathrm{C}$ under a relative humidity of $50-60 \%$.

\section{Preparation of Agrobacterium tumefaciens}

The A. tumefaciens strain LBA4404 harboring the plasmid pBI121, which carries AFP$C H I$ and $n p t I I$ genes, was used for the transformation (Bezirganoglu et al., 2013). The $A F P-C H I$ gene is driven by the cauliflower mosaic virus (CaMV) $35 \mathrm{~S}$ promoter and terminator by nopaline synthase (NOS) (Figure 1). Agrobacterium was initially grown at $28^{\circ} \mathrm{C}$ in Luria-Bertani (LB) broth solid medium containing $50 \mathrm{mg} / \mathrm{L}$ kanamycin and $25 \mathrm{mg} / \mathrm{L}$ streptomycin. After 2 days of incubation, a single bacterial colony of Agrobacterium was inoculated into freshly prepared LB broth containing appropriate antibiotics $(50 \mathrm{mg} / \mathrm{L}$ kanamycin and $25 \mathrm{mg} / \mathrm{L}$ streptomycin). The bacteria were grown in the dark at $28^{\circ} \mathrm{C}$ for $16-20 \mathrm{~h}$ in an incubator shaker at $225 \mathrm{rpm}$. After incubation, $20 \mathrm{~mL}$ culture was transferred into a $250 \mathrm{~mL}$ sterile Erlenmeyer flask containing 100 $\mathrm{mL} \mathrm{LB}$ broth with $50 \mathrm{mg} / \mathrm{L}$ kanamycin; the culture was incubated until $\mathrm{OD}_{600}$ reached $0.6,0.8$, and 1.0. Later, $15 \mathrm{~mL}$ culture was harvested and centrifuged to pellet the bacteria. The supernatant was discarded, and the pellets were re-suspended in $20 \mathrm{~mL}$ MS liquid medium. The cotyledon explants were then submerged in the bacterial suspension for $30 \mathrm{~min}$, blotted onto autoclaved filter paper to remove excess Agrobacterium, and then transferred onto the co-culture medium containing MS basal medium, pH 5.8, and $0.7 \%$ agar supplemented with $0.2 \mathrm{mg} / \mathrm{L}$ benzyl adenine (BA) and 0.2 $\mathrm{mg} / \mathrm{L}$ naphthalene acetic acid (NAA) without antibiotics. They were kept there for 2, 3, or 4 days at $28^{\circ} \mathrm{C}$ to assess the effects of co-cultivation time on transformation efficiency. 


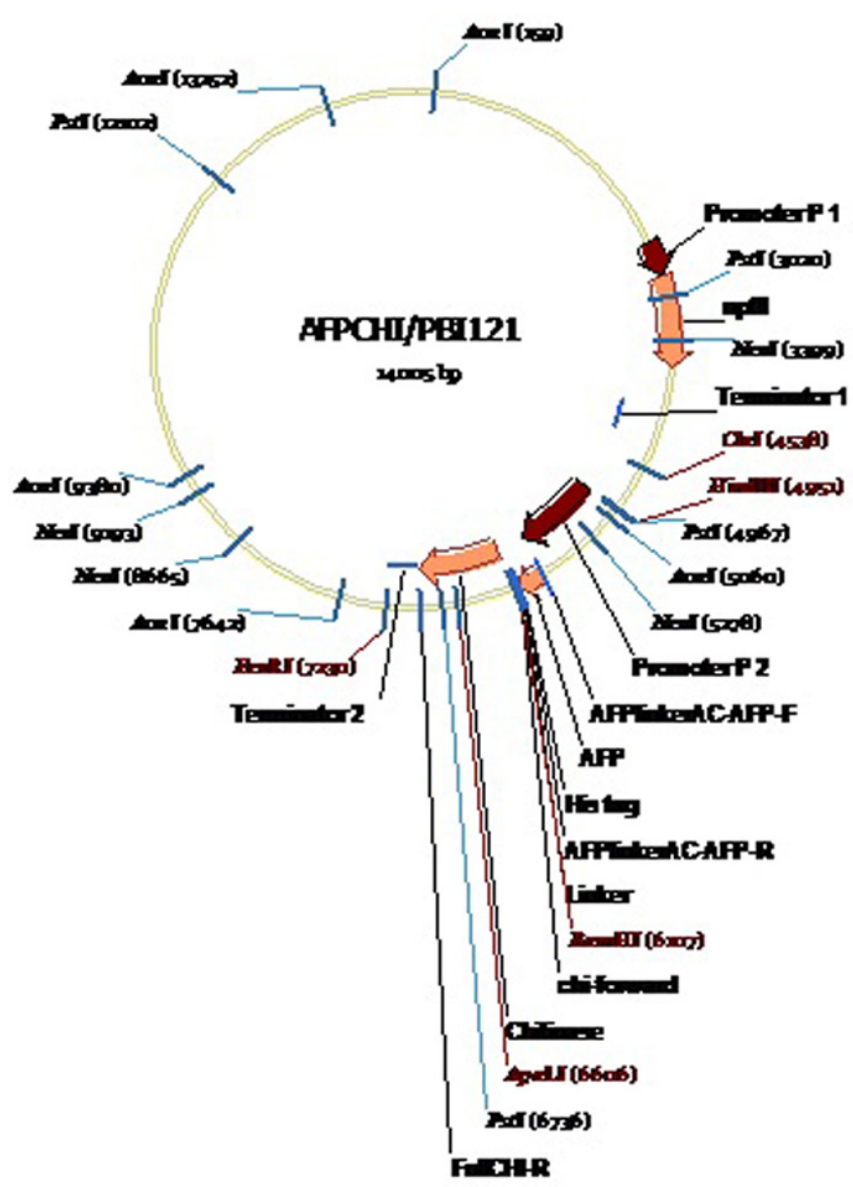

Figure 1. Schematic drawings of the plasmid vector used for transformation of Cucumis melo L. var. makuwa cv. 'Silver light' with the AFP-CHI gene isolated from papaya. The target genes, $A F P$ and $C H I$, were restricted into pBI121 binary vector in between 35S promoter and Nos terminator. $R B=$ right border; Nos = promoter of Nos gene; $n p t \mathrm{II}=$ neomycin phosphotransferase II; Nos = terminator of $N o s$ gene; $35 \mathrm{~S}=$ cauliflower mosaic virus $35 \mathrm{~S}$ promoter; $A F P=$ papaya antifungal protein gene; $C H I=$ papaya chitinase gene; $L B=$ left border.

\section{Selection, regeneration, and acclimatization}

Two days after the Agrobacterium infection, the explants were washed with sterile distilled water containing $300 \mathrm{mg} / \mathrm{L}$ carbenicillin for $5 \mathrm{~min}$ and further rinsed in sterile distilled water for 5 min to remove the antibiotics; then, they were blot-dried on sterile filter paper and transferred onto Petri dishes containing $200 \mathrm{mg} / \mathrm{L}$ kanamycin as selection media. Non-inoculated explants were cultured in the same way as the explants inoculated with Agrobacterium as a routine control experiment. The explants were sub-cultured in fresh medium of the same composition 2 weeks after infection. Five weeks after the transformation, shoots started to appear from the explants, and these were ready to be handled over the following 3 weeks. Kanamycin-resistant shoots were transferred to the shoot outgrowth medium (MS 
medium supplemented with $0.01 \mathrm{mg} / \mathrm{L}$ NAA, $0.1 \mathrm{mg} / \mathrm{L} \mathrm{BA}, 200 \mathrm{mg} / \mathrm{L}$ carbenicillin, $200 \mathrm{mg} / \mathrm{L}$ kanamycin, and $0.7 \%$ agar) and allowed to develop for 2 weeks. Regenerated shoots exhibiting green explants were evaluated as putatively transgenic; shoots showing red explants were considered as escapes. Adventitious shoots were micropropagated on the shoot outgrowth medium to generate multiple shoots. The healthy, green shoots were transferred to the rooting medium [MS medium with $0.5 \mathrm{mg} / \mathrm{L}$ indole butyric acid (IBA)].

\section{Polymerase chain reaction (PCR)}

$\mathrm{T}_{1}$ transgenic plants were analyzed by PCR for the presence of $C H I$. The primer pair CHI-F (5'-ATG TCG CCAAAC AAT GCC TTA CTC CTT TCG-3') and CHI-R (5'-TTA GTG GTG GTG GTG GTG GTG-3') was used in this study. PCR was performed in a 50- $\mu$ L solution comprising $200 \mathrm{ng} 1 \mu \mathrm{L}$ melon genomic DNA, $4 \mu \mathrm{L} 2.5 \mathrm{mM}$ dNTPs, 10X $5 \mu \mathrm{L}$ PCR buffer, 5 unit $/ \mu \mathrm{L} 0.5 \mu \mathrm{L}$ BioVan Tag polymerase, $1 \mu \mathrm{L} 10 \mathrm{mM}$ each primer, and $37.5 \mu \mathrm{L} \mathrm{ddH_{2 }} \mathrm{O}$. The cycling conditions for the PCR reaction were as follows: $95^{\circ} \mathrm{C}$ for $45 \mathrm{~s}, 58^{\circ} \mathrm{C}$ for $45 \mathrm{~s}$, and $72^{\circ} \mathrm{C}$ for $1 \mathrm{~min}$, for 30 cycles. The PCR products were visualized with the use of $0.8 \%(\mathrm{w} / \mathrm{v})$ agarose gel electrophoresis.

\section{Southern blot analysis}

Total genomic DNA was isolated from $\mathrm{T}_{1}$ transgenic young leaves using a modified CTAB method as described by Sambrook et al. (1989). Thirty micrograms DNA were digested with HindIII, electrophoresed on $0.8 \%$ (w/v) agarose gel, and DNA transferred onto a nylon membrane (Roche Molecular Biochemicals, Mannheim, Germany). The CHI probe was labeled by PCR using digoxigenin-11-2'-deoxyuridine-5'-triphosphate (DIG-11-dUTP) in accordance with manufacturer instructions (Boehringer Mannheim, Pleasanton, CA, USA). The procedures for hybridization, washing, and detection were conducted according to manufacturer instructions.

\section{RESULTS AND DISCUSSION}

\section{Improved transformation frequency}

The establishment of an efficient transformation system, especially for a recalcitrant crop such as melon, is a crucial step for the generation of transgenic plants. As shown in previous studies, the use of suitable explants is a critical factor in genetic transformation. In the transformation of melon species, cotyledon explants are often preferable to other explant sources because of their easy availability. In this report, we used cotyledon explants, with some modifications to optimize gene transformation and regeneration parameters, such as Agrobacterium density, antibiotic concentration, and the effects of inoculation times and cocultivation times during the transformation process. Many other melon transformation studies have shown optimum inoculation times of 20 to $30 \mathrm{~min}$ (Ayub et al., 1996; Guis et al., 2000) depending on the Agrobacterium strain used, the concentration of the bacterial suspension, plant species, and explants size. We tested 10,20, and $30 \mathrm{~min}$ inoculation times. The explants inoculated for $30 \mathrm{~min}$ gave the highest transformation frequency, while shorter inoculation times led to a reduction in transformation frequency (data not shown). Therefore, an inocu- 
lation time of 30 min for cotyledon explants obtained from 20 seeds on agar medium was used throughout the transformation process (Figures 2a and b). In Agrobacterium transformation, gene delivery occurs mainly during co-cultivation. Optimal co-cultivation with an effective Agrobacterium concentration in an appropriate medium for an adequate time under suitable environmental conditions is critical for efficient gene delivery. Numerous factors can improve transformation frequency, including temperature, lighting conditions, co-cultivation period, and bacterial population density during the co-cultivation treatments. Among the parameters studied, the time of the co-culture was the most important factor for enhancing the frequency of melon transformation. A co-culture period of 2-6 days for explants of melon plants is generally considered suitable for Agrobacterium-mediated genetic transformation and is recognized as effective for transformation. With an extended co-culture period, bacterial overgrowth caused explant death and reduced the number of regenerated shoots. The influence of co-cultivation time on Agrobacterium-mediated genetic transformation has been reported in many plant species, such as Citrullus lanatus, Cucumis melo L., and Musa sp. In the present study, a co-culture period of two days was identified to be optimal (Figure 2c). This phenomenon is consistent with findings of previous research (Nishibayashi et al., 1996). One commonly observed problem with Agrobacterium-mediated gene transfer is the overgrowth of tissue cultures with Agrobacterium. This problem was overcame by using a liquid culture system in the initial co-culture medium. This procedure also allows high throughput in the inoculation and removal of excess Agrobacteria. Inoculated explants were washed with sterilized distilled water containing $300 \mathrm{mg} / \mathrm{L}$ carbenicillin and then blot-dried on sterile Whatman No. 1 filter paper to remove excess bacteria. This is an effective way to inhibit the overgrowth of Agrobacterium from the inoculated explants. In the present study, $300 \mathrm{mg} / \mathrm{L}$ carbenicillin was suitable and effective in suppressing the overgrowth of the Agrobacterium. After the explants that had been inoculated with Agrobacterium underwent two days of co-culture, those that swelled and turned green were placed in the selection medium.

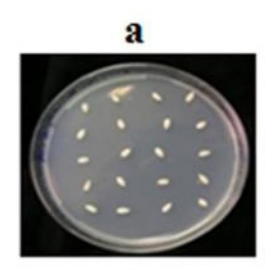

e

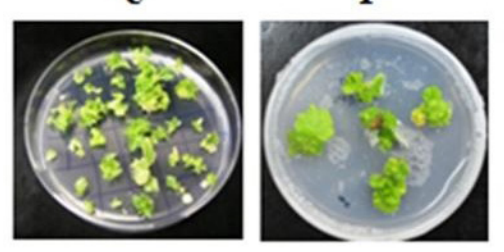

b

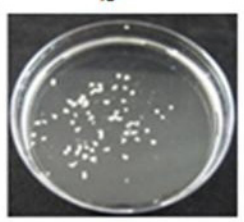

f

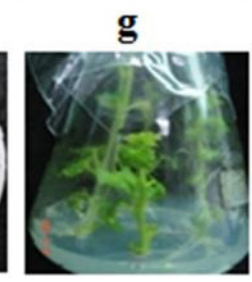

c

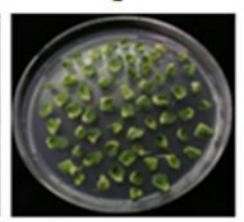

g

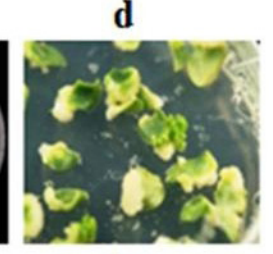

h

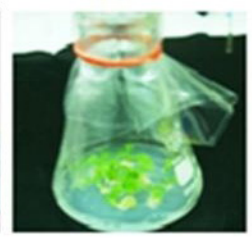

Figure 2. Overview of the steps in the Agrobacterium-mediated transformation of melon plants. a. Place seeds onto germination medium and incubation in dark at room temperature for two days. b. Agrobacterium inoculation culture (O.D. $=0.06$ ) for $30 \mathrm{~min}$. (c) Place explants onto co-culture medium and incubation in light at $28^{\circ} \mathrm{C}$ for two days. d. Place explants onto selection medium and incubation in light at $28^{\circ} \mathrm{C}$ for two weeks. e. Place small shoots onto shoot outgrowth medium and incubation in light at $28^{\circ} \mathrm{C}$ for two weeks. f. Place large shoots outgrowth onto medium and incubation in light at $28^{\circ} \mathrm{C}$ for two weeks. g. Place plantlets onto shoots outgrowth onto medium in light at $28^{\circ} \mathrm{C}$ for one week. h. Place plantlets onto root initiation medium in light at $28^{\circ} \mathrm{C}$ for one week. 
Various forms of antibiotics, and at different concentrations, have either positive or negative effects on shoot regeneration and genetic transformation. Therefore, evaluating the effects of antibiotics on shoot regeneration is a prerequisite for any plant transformation effort. The use of the proper concentration of antibiotics in the selection medium is one of the most critical steps in genetic transformation. Most melon transformation studies, such as that of Galperin et al. (2003), have used kanamycin as the selectable marker. In the present study, the optimal concentrations of kanamycin for the selection and regeneration of transgenic shoots were determined by testing the explants on selection medium supplemented with different kanamycin concentrations $(100,200$, and $300 \mathrm{mg} / \mathrm{L})$. Among the different concentrations of kanamycin tested, $200 \mathrm{mg} / \mathrm{L}$ was chosen as the most suitable concentration for the selection of Oriental melon transformants (Figure 2d). Several research groups have reported that "escapes" are particularly common in melon. The high frequency of "escapes" in melon transformation may depend on the genotype and the concentration of kanamycin used as the selection agent. This phenomenon has also been reported in other studies (Akasaka-Kennedy et al., 2004; Ntui et al., 2010). To reduce the negative impact of "escapes" on the regeneration of transgenic shoots, and to inhibit the formation of false transformants, it is important to apply $200 \mathrm{mg} / \mathrm{L}$ kanamycin to allow the proliferation of transgenic shoots. The secondary shoots produced from the primary shoots were subjected to three successive propagation cycles with the same level of selection medium (200 mg/L kanamycin). After three sub-cultures, false transgenic shoots and escapes-type shoots turned red and gradually perished, while the transgenic shoots continued to survive and grow normally (Figure 2e, f, and g). We found it highly effective to carry out selection at a high kanamycin concentration because cotyledon explants are inherently moderately resistant to kanamycin. A kanamycin concentration of $200 \mathrm{mg} / \mathrm{L}$ was initially used to select resistant explants, and this concentration was found to be suitable to obtain transgenic shoots. This result is in agreement with previous reports (Dong et al., 1991; Vallés and Lasa, 1994). There was no escape observed since a high concentration of kanamycin was used as the selection medium. All of the potential escapes were discarded during the early stage of the culturing period in this study.

\section{Overcoming vitrification and improved rooting}

In the cultivation of transgenic shoots in vitro, vitrification is one of the problems found in melon transformation studies. Vitrification is observed in swollen translucent leaves and brittle stems. Thus, in some transgenic shoots developed in vitro, the formed leaves have abnormal tissue and are water-soaked, translucent, and glassy (Huang et al., 2011). Vitrified transgenic shoots are difficult to root and lead to losses in plantlets after their transfer to the greenhouse. Several causes of vitrification have been suggested, such as high cytokinin levels, high light, low temperature, the type of culture vessels, and the concentration of agarose. The vitrification of plants in vitro is mostly explained by a low concentration of agar and a high relative humidity in culture vessels, the latter seeming to be the most serious problem in in vitro culture. Vitrification can be prevented more effectively by using a higher concentration of agarose, bottom cooling of culture vessels, and with the use of growth retardants (Ziv, 1991). We were able to reduce vitrification by increasing the agarose concentration from 0.7 to 0.8 $\mathrm{g} / \mathrm{L}$. Using a high agarose concentration $(0.8 \%)$, increasing the volume of selection medium in the Petri dish, and sealing the Petri dishes with Urgo pore tape instead of parafilm, the vitrifica- 
tion was eliminated in the present study. Poor in vitro roots formation were also eliminated by obtaining transgenic shoots without vitrification. In our study, we used half-strength MS medium containing IBA and a lower concentration of sucrose, which produced $100 \%$ success in rooting experiments. Root formation was faster on rooting medium, with roots being induced less than 6 days following transfer to the rooting medium (Figure 2h).

\section{PCR and Southern blot analyses of $T_{1}$ plants}

As soon as a shoot was confirmed as transgenic via PCR detection, the shoot was transferred to rooting medium lacking antibiotics for further analysis. $\mathrm{T}_{\mathrm{o}}$ comparison confirmed that the transgenes were transmitted to the next generation. $T_{0}$ plants were grown to maturity, self-pollinated to produce $T_{1}$ seeds, and the progeny were grown to produce $T_{1}$ transgenic plants (Figure 3 ). PCR experiments again detected the presence of the $\mathrm{CHI}$ gene in $\mathrm{T}_{1}$ plants. Plants of the $\mathrm{T}_{1}$ generation were found to be PCR positive for $\mathrm{CHI}$ (Figure 4). Southern blot analysis confirmed that the $\mathrm{CHI}$ gene was stably transmitted to $\mathrm{T}_{1}$ plants (Figure 5). These molecular analyses confirmed that transgenic $\mathrm{T}_{0}$ melon plants produced transgenic $\mathrm{T}_{1}$ melon progeny that displayed classic inheritance patterns. A total of 11 transgenic $\mathrm{T}_{\mathrm{o}}$ melon lines that were generated with $\mathrm{pBI} 121-A F P$ CHI were obtained. Of the 1442 cotyledon explants that were inoculated with the Agrobacterium overnight culture, 109 proliferated on the shoot outgrowth medium containing $200 \mathrm{mg} / \mathrm{L}$ kanamycin. The transformation efficiency, calculated based on PCR-positive plants, was $0.8 \%$ (Table 1), which is similar to results previously reported (Han et al., 2005). Although the overall transformation efficiency of our method is very low, our study showed that transgenic melon plants could be produced successfully through Agrobacterium-mediated genetic transformation.
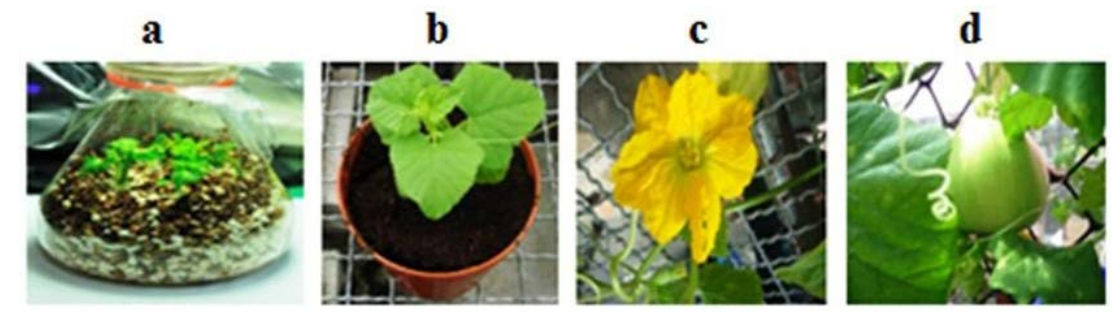

Figure 3. Production of transgenic melon plants via Agrobacterium-mediated transformation. a. Place plantlets onto vermiculite medium in light at $28^{\circ} \mathrm{C}$ for one week. b. Transgenic melon plant in the greenhouse. c. A flower on a transgenic melon plant in the greenhouse. d. Fruit on a transgenic melon plant in the greenhouse.

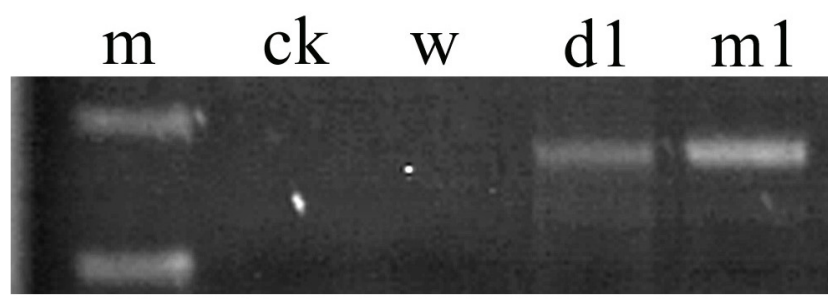

Figure 4. $\mathrm{PCR}$ analysis of transgenic $\mathrm{T}_{1}$ melon plants with $C H I$. Lanes $M=$ molecular marker (Gen-KB DNA Ladder); $\mathrm{ck}=$ non-transformant melon; $\mathrm{w}=$ water; $\mathrm{d} 1=$ transgenic melon plant; $\mathrm{m} 1=$ transgenic melon plant. 


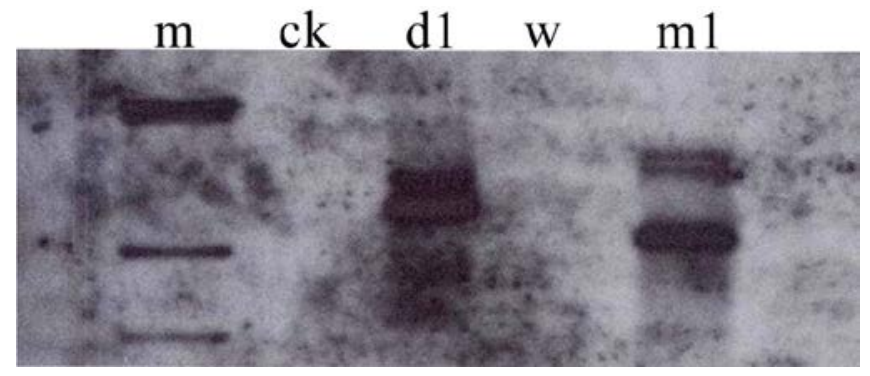

Figure 5. Southern blot analysis for the presence of the $C H I$ gene in transgenic $\mathrm{T}_{1}$ melon plants. Lanes $M=$ molecular marker; ck = non-transformant melon; $\mathrm{w}=$ water; $\mathrm{d} 1$ = transgenic melon plant; $\mathrm{m} 1$ = transgenic melon plant.

Table 1. Transformation frequency using AFPCHI/pBI121/LBA4404 and kanamycin selection.

\begin{tabular}{lcccc}
\hline Experiment runs & No. explants & No. of regenerated shoots & PCR positive & Transformation efficiency (\%)* \\
\hline 1 & 333 & 26 & 2 & 0.6 \\
2 & 387 & 32 & 3 & 0.8 \\
3 & 350 & 22 & 2 & 0.6 \\
4 & 372 & 29 & 4 & 1.1 \\
Total & 1442 & 109 & 11 & 0.8 \\
Average & & & & 0.8 \\
\hline
\end{tabular}

*Transformation efficiency $=$ PCR positive plants $/$ Total explant numbers $\mathrm{x} 100$.

\section{REFERENCES}

Akasaka-Kennedy Y, Tomita K and Ezura H (2004). Efficient plant regeneration and Agrobacterium-mediated transformation via somatic embryogenesis in melon (Cucumis melo L.). Plant Sci. 166: 763-769.

Ayub R, Guis M, Ben AM, Gillot L, et al. (1996). Expression of ACC oxidase antisense gene inhibits ripening of cantaloupe melon fruits. Nat. Biotechnol. 14: 862-866.

Bezirganoglu I, Hwang SY, Fang TJ and Shaw JF (2012). Transgenic lines of melon (Cucumis melo L. var. makuwa cv. 'Silver Light') expressing antifungal protein and chitinase genes exhibit enhanced resistance to fungal pathogens. Plant Cell Tissue Organ. Cult. 112: 227-237.

Bordas M, Montesinos C, Dabauza M, Salvador A, et al. (1997). Transfer of the yeast salt tolerance gene HAL1 to Cucumis melo L. cultivars and in vitro evaluation of salt tolerance. Transgenic Res. 6: 41-50.

Choi JY, Shin JS, Chung YS and Hyung NI (2012). An efficient selection and regeneration protocol for Agrobacteriummediated transformation of oriental melon (Cucumis melo L. var. makuwa). Plant Cell Tissue Organ. Cult. 110: 133-140.

Chovelon V, Restier V, Giovinazzo N, Dogimont C, et al. (2011). Histological study of organogenesis in Cucumis melo L. after genetic transformation: why is it difficult to obtain transgenic plants? Plant Cell Rep. 30: 2001-2011.

Dong JZ, Yang MZ, Jia SR and Chua NH (1991). Transformation of melon (Cucumis melo L.) and expression from the cauliflower mosaic virus 35S promoter in transgenic melon plants. Nat. Biotechnol. 9: 858-863.

Fang G and Grumet R (1990). Agrobacterium tumefaciens mediated transformation and regeneration of muskmelon plants. Plant Cell Rep. 9: 160-164.

Fuchs M, Klas F, McFerson J and Gonsalves D (1998). Transgenic melon and squash expressing coat protein genes of aphid-borne viruses do not assist the spread of an aphid non-transmissible strain of cucumber mosaic virus in the field. Transgenic Res. 7: 449-462.

Galperin M, Patlis L, Ovadia A, Wolf D, et al. (2003). A melon genotype with superior competence for regeneration and transformation. Plant Breed. 122: 66-69.

Guis M, Amor MB, Latche A, Peche JC, et al. (2000). A reliable system for the transformation of cantaloupe charentais melon (Cucumis melo L var. cantalupensis) leading to a majority of diploid regenerants. Scientica Hort. 84: 91-99.

Han JS, Kim CK, Park SH, Hirschi KD, et al. (2005). Agrobacterium-mediated transformation of bottle gourd (Lagenaria siceraria Stand1.). Plant Cell Rep. 23: 692-698. 
Huang YC, Chiang CH, Li CM and Yu TA (2011). Transgenic watermelon lines expressing the nucleocapsid gene of Watermelon silver mottle virus and the role of thiamine in reducing hyperhydricity in regenerated shoots. Plant Cell Tissue Organ. Cult. 106: 21-29.

Nishibayashi S, Kareko H and Hayakawa T (1996). Transformation of cucumber (Cucumis sativus L.) plants using Agrobacterium tumefaciens and regeneration hypocotyls explants. Plant Cell Rep. 15: 809-814.

Nora FR, Peters JA, Schuch MW, Lucchetta L, et al. (2001). Melon regeneration and transformation using an apple ACC oxidase antisense gene. Rev. Bras. Agrociêcia 7: 201-204.

Ntui VO, Thirukkumaran G, Azadi P, Khan RS, et al. (2010). Stable integration and expression of wasabi defensin gene in "Egusi" melon (Colocynthis citrullus L.) confers resistance to Fusarium wilt and Alternaria leaf spot. Plant Cell Rep. 29: 943-954.

Nuñez-Palenius HG, Gomez-Lim M, Ochoa-Alejo N, Grumet R, et al. (2008). Melon fruits: genetic diversity, physiology, and biotechnology features. Crit. Rev. Biotechnol. 28: 13-55.

Ren Y, Bang H, Curtis IS, Gould J, et al. (2012). Agrobacterium-mediated transformation and shoot regeneration in elite breeding lines of western shipper cantaloupe and honeydew melons (Cucumis melo L.). Plant Cell Tissue Organ. Cult. 108: 147-158.

Sambrook J, Fritsch EF and Maniatis T (1989). Molecular Cloning: A Laboratory Manual. 2nd ed. Cold Spring Harbor Laboratory Press, New York.

Vallés MP and Lasa JM (1994). Agrobacterium-mediated transformation of commercial melon (Cucumis melon L. cultivar Amerillo Oro). Plant Cell Rep. 13: 145-148.

Wu HW, Yu TA, Raja JA, Wang HC, et al. (2009). Generation of transgenic oriental melon resistant to Zucchini yellow mosaic virus by an improved cotyledon-cutting method. Plant Cell Rep. 28: 1053-1064.

Ziv M (1991). Vitrification: Morphological and Physical Disorders of In-Vitro Plants. In: Micropropagation, Technology and Application (Debergh PC and Zimmerman RH, eds.). Kluwer Academic Publishers, London, 45-69. 